\title{
Functionalized Carbon Nanofiber Based Conducting Nanocomposites for Biomedical Applications
}

\author{
V. Monica ${ }^{1}, *$ Dr. Amitava Bhattacharyya ${ }^{2}$ and Mrs.K.Chandra Devi ${ }^{1}$ \\ $\left\{\right.$ monicansnt@gmail.com ${ }^{1}$, abh@psgias.ac.in ${ }^{2}$, kcd.ece@psgtech.ac.in $\left.{ }^{1}\right\}$ \\ Dept of Electronics and Communication Engineering PSG College of Technology Coimbatore, \\ India $^{1}$, Associate Professor, PSG Institute of Advanced Studies Coimbatore, India ${ }^{2}$, Dept of Electronics \\ and Communication Engineering PSG College of Technology Coimbatore, India ${ }^{3}$.
}

\begin{abstract}
The Carbon-based nanomaterials play a vital role because of they are biocompatible, economical, efficient, stable and environmental-friendly nature, which makes superior to use them in biotechnology, biomedical, electronics and electrical applications. Under the classification of carbon- based nanomaterials, carbon nanofibers (CNFs) are the predominantly used nanomaterial in many healthcare applications due to nontoxicity. CNFs are easily and uniformly dispersible in nature when compared to other carbon-based nanomaterials. In this study, the first part discusses about the acidfunctionalization of CNFs. The second part discusses the preparation and characterization of Functionalized CNF (F- CNF)-Gelatin/PVA hydrogel. And, the final part concentrates to enhance the electrical conductivity of the hydrogel. The main objective of this work is to study the effect of hydrogel formed via acid functionalized CNF as a crosslinker in the conducting nanocomposite. Additionally, analysis on functionality of the prepared hydrogel on ECG electrode application was discussed in this paper. In comparison with conventional nano-based electrodes, the current work with F-CNF based conducting nanocomposite hydrogel patch has better performance which involves usage of less harsh chemicals. It can able to efficiently monitor biosignals, such as in electromyography and electroencephalography.
\end{abstract}

Keywords: Carbon nanofibers, Acid functionalized Carbon nanofibers, Polyvinyl alcohol, Gelatin, Hydrogels, Electrocardiogram (ECG) electrodes.

\section{Introduction}

Electrocardiogram (ECG) is a simple test used to measure the electrical activity of the heart using external ECG electrodes. The electrode comprises an electrode, an adherent and a cable connector. Most commonly used conventional ECG electrodes are reusable wet $\mathrm{Ag} / \mathrm{AgCl}$ electrodes. Though the electrodes show remarkable low skin impedance with good signal stability and reproducibility, it can dry out over a period of time resulting in observational errors due to the motion artifact and contact resistance. Latest research resolves the issues by developing polymeric nanocomposite-based hydrogels for measuring the signals. These hydrogels are effective, biocompatible, reproducible, flexible and stable, and provides stable electrical and mechanical performances.

Polymer nanocomposite (PNC) is known to be the foundation for nanotechnology. The attractive properties such as mechanical, electrical and thermal properties, enables them use in 
numerous field of applications. PNC is a composite material consisting of polymer matrix and reinforcement filler (nanofiller or nanomaterial) [1].

Combination of nanoscale reinforcement filler and polymer matrix enables excellent functional and mechanical properties, yet poor dispersion and weak interfacial interactions between the filler and polymer matrix were the major issues limiting the improvement of PNC performance.

In order to overcome these issues, there are various ways such as surface modification, surfactant adsorption, polymer wrapping, even though it remains a great challenge for achieving high performance PNC. Aside from the limitations, PNC plays a major role in many fields, especially for biomedical applications. Recently, researchers successfully developing successful approach "bioinspired concept" for creating high performance polymer nanocomposites with different reinforcement fillers (nanoclay, carbon nanotubes, carbon nanofibers and graphene). Bioinspired PNC provides layered hierarchical micro/nano-scaled structure with excellent characteristic behaviour [2]. In this work, Gelatin/PVA and carbon nanofibers (CNFs) were used as polymer matrix and reinforcement filler, respectively.

One of the most commonly used carbon-based nanomaterial is carbon nanotubes (CNTs). Though the CNTs are quite familiar, biocompatibility with respect to the human body is questionable $[3,4]$. The aggregation condition of CNFs are far better than CNTs due to their more easily and uniformly dispersible nature with polymers [5-8]. CNFs are $\mathrm{sp}^{2}$-based linear, noncontinuous filaments. The form of CNFs is pyrrolitically stripped, platelets (conical). The length and diameter of CNFs is $20-200 \mathrm{~mm}$ and $100 \mathrm{~nm}$, respectively. They have excellent electron transfer ability and mechanical strength, biocompatible and economical. Two major methods were proposed to improve dispersion quality of nanofiller in the polymer matrix: chemical method (covalent bonding) and physical method (noncovalent bonding), because direct mixing of nanofiller with polymer matrix will cause aggregation and defects due to Van der Waals interaction and high aspect ratio of nanofiller [9]. Directly mixing nanofiller with polymer matrix will cause unwanted aggregation and defects induced by Van der Waals interaction and high aspect ratio of nanofiller. In order to overcome unwanted aggregation, two major methods were proposed to improve dispersion quality of nanofiller in the polymer matrix: covalent (chemical functionalization) and noncovalent modification (physical treatment or surfactant treatment) [6].

Polymer matrix and Gelatin

Gelatin is one of the most commonly used biopolymers. The word gelatin is derived from the Latin word "gelatus" which describes its characteristic property, i.e. gel formation in water [10]. It is a cost-effective animal protein. The gelatin protein structure consists of a triple helix and higher helix content increases the physical properties required for film [11] [12]. It consists of mixture of polypeptide chains with different compositions and molecular weights, as shown in fig. 2. 
Availability of PVA in the market will be in different range based on the viscosity and degree of hydrolysis [7, 15]. The number of hydroxyl groups present in the PVA polymer governs the physicochemical and mechanical attributes of PVA [16]. The degree of hydrolysis of PVA was determined by reaction period of saponification [17]. PVA is most widely used in the synthesis of poly(vinyl butyral) (PVB) which is a low-cost flexible thermoplastic used as strong adhesive, and vinylon fibers which is a manmade heat and chemical resistant fiber (also known as Juche fiber) [18].

\section{EXPERIMENTAL METHODS}

\section{Materials}

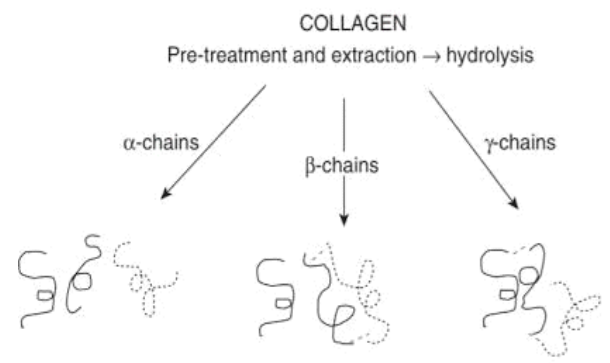

Fig. 1. shows gelatin protein structure consisting of mixture of polypeptide chains with different compositions and molecular weights (Haug et al. 2011).

The figure shows the three major fragments present in gelatin: free $\alpha$-chains, $\beta$-chains (two $\alpha$-chains are covalently linked) and $\gamma$-chains (three $\alpha$-chains are covalently linked), which means that gelatin is not a monodisperse protein. Gelatin is mainly used as a highly efficient bio-surfactant to functionalize carbon nanofibers (CNFs), resulting in nanocomposite with remarkable improved mechanical, electrical and processing properties. Combining CNFs with gelatin improves wettability and surface energy compared with CNFs[8].

- Polyvinyl alcohol

In 1924, Hermann and Haehnel synthesized Polyvinyl alcohol (PVA). It was prepared by saponifying poly(vinyl ester) with sodium hydroxide [13]. PVA is synthetic, odorless, nontoxic, biocompatible, water-soluble, cream or white granular or powdered polymer [14]. The chemical formula of PVA: $[\mathrm{CH} 2 \mathrm{CH}(\mathrm{OH})] \mathrm{n}$. It has outstanding oxygen and aroma barrier properties, mechanical strength, optical properties, dielectric strength and charge storage ability [13] as well as resistant to solvents, oil and grease. The mechanical, optical and electrical properties can be improved with the addition of dopants such as nano-scale based particles.

TABLE I. PHYSICAL AND CHEMICAL PROPERTIES OF PVA.

\begin{tabular}{|c|c|c|}
\hline Parameters & Description & \multirow{2}{*}{ References } \\
\cline { 1 - 2 } & $\begin{array}{c}\text { Creamy to } \\
\text { whitish,granular,powder }\end{array}$ \\
\cline { 1 - 2 } & $20000-400000 \mathrm{~g} / \mathrm{moL}$ & \\
\hline Molecularweight & Solubleinwater & \\
\hline Solubility &
\end{tabular}




\begin{tabular}{|c|c|}
\hline Appearance & $\begin{array}{c}\text { Creamy to } \\
\text { whitish,granular,powder }\end{array}$ \\
\hline Boilingpoint & $2288^{\circ} \mathrm{C}$ \\
\hline Density & $1.19-1.31 \mathrm{~g} / \mathrm{cm}^{3}$ \\
\hline Bulkdensity & $641 \mathrm{~kg} . \mathrm{s} / \mathrm{m}^{3}$ \\
\hline Stabilitytosunlight & Excellent \\
\hline $\begin{array}{c}\text { Glass } \\
\text { transitiontemperature }\end{array}$ & $758 \mathrm{C}-858^{\circ} \mathrm{C}$ \\
\hline
\end{tabular}

Cabon nanofibers having diameter $100 \mathrm{~nm}$ and length 20 -

$30 \mu \mathrm{m}$ was supplied by Sigma-Aldrich. Sulphuric acid having molecular weight of 98.08 $\mathrm{g} / \mathrm{mol}$ and purity of $98 \%$ was supplied by Loba chemie. Potassium permanganate having molecular weight of $158.034 \mathrm{~g} / \mathrm{mol}$ was supplied by Fisher scientific. Sodium nitrate purified molecular weight of

$84.99 \mathrm{~g} / \mathrm{mol}$ was supplied by merck. Gelatin for bacteriology was supplied by Himedia. Hydrogen peroxide $6 \% \mathrm{~W} / \mathrm{V}$ was supplied by Isochem laboratories.

\section{- Synthesis}

- Acid functionalization of carbon nanofibers

$0.5 \mathrm{~g}$ Carbon nanofibers, $50 \mathrm{~mL}$ Sulphuric acid (H2SO4) and $4 \mathrm{~g}$ Sodium nitrate (NaNo3) were measured and added into the beaker. The beaker was placed on a magnetic stirrer and allowed to stir for 30 minutes at $300 \mathrm{rpm}$ under an ice bath. After 30 minutes of stirring, $6 \mathrm{~g}$ Potassium permanganate (KMnO4) was carefully added into the beaker. The solution was subjected to ultrasonication treatment for 30 minutes. Again, the solution was stirred on the magnetic stirrer for 3 hours at $300 \mathrm{rpm}$ under the ice bath. The solution was carefully mixed with $200 \mathrm{~mL}$ de-ionized water to stop the reaction. The solution was allowed for overnight at room temperature. $50 \mathrm{~mL} 6 \%$ hydrogen peroxide $(\mathrm{H} 2 \mathrm{O} 2)$ was added to reduce the un-reacted $\mathrm{KMnO}$. The solution was washed twice with diluted hydrochloric acid and thrice with deionized water. The obtained solution was filtered using Whatman filter paper. The filtrate was dried in a vacuum oven at $120{ }^{\circ} \mathrm{C}$ for 60 hours. Dried sample was ground using mortar and weighed. The obtained acid functionalized carbon nanofiber powder was stored for future use.

- Preparation of F-CNF/Gelatin hydrogel

$0.9 \mathrm{~g}$ Gelatin was dissolved into $8 \mathrm{~mL}$ distilled water and stirred using magnetic stirrer at $80^{\circ} \mathrm{C}$ for 3-4 hours (until complete dissolution of Gelatin). Allow the mixture to reach room temperature. $0.01 \mathrm{~g}$ F-CNF was separately dissolved in $2 \mathrm{~mL}$ distilled water and manually mixed. Prepared gelatin aqueous solution was slowly added to the F-CNF solution and subjected to ultrasonication treatment for 30 mins. Then, the solution was stirred with the magnetic stirrer for $1 \mathrm{hr}$. Subsequently, the final solution was cast onto a Petri dish and left at room temperature for $24 \mathrm{~h}$ to form a thin film. Finally, the film was peeled off from the mould.

- Preparation of F-CNF/PVA hydrogel

1 g Polyvinyl alcohol (PVA) was dissolved into $8 \mathrm{~mL}$ distilled water and stirred using magnetic stirrer at $90^{\circ} \mathrm{C}$ for $3-4$ hours (until complete dissolution of PVA). Allow the

mixture to reach room temperature. $0.01 \mathrm{~g}$ F-CNF was separately dissolved in $2 \mathrm{~mL}$ distilled water and manually mixed. Prepared PVA aqueous solution was slowly added to the F-CNF solution and subjected to ultrasonication treatment for 30 mins. Then, the solution was stirred with the magnetic stirrer for $1 \mathrm{hr}$. Subsequently, the final solution was cast onto a Petri dish and left at room temperature for $24 \mathrm{~h}$ to form a thin film. Finally, the film was peeled off from the mould. 


\section{- Optimization}

- Optimization of F-CNF/Gelatin

For this experiment, different concentrations ( $0 \mathrm{wt} \%$ and $4 \mathrm{wt} \%$ ) of F-CNF added to preprepared gelatin aqueous solutions. The solution was subjected to ultasonication treatment for 30 mins and stirred using magnetic stirrer for 1 hour. The obtained solutions were compared with $\mathrm{P}-\mathrm{CNF} / \mathrm{Gelatin}$ solution and characterized.

- Optimization of $F-C N F / P V A$

For this experiment, different amount ( $0 \mathrm{wt} \%$ and $4 \mathrm{wt} \%)$ of F-CNF added to preprepared PVA aqueous solutions. The solutions were subjected to ultasonication treatment for 30 mins and stirred using magnetic stirrer for 1 hour. The obtained solutions were compared with P-CNF/PVA solution and characterized.

\section{Characterization}

Cross-section morphology of prepared F-CNF was analyzed using scanning electron microscopy (SEM, ZEISS, EVO 18, Germany). The samples $(1 \times 1 \mathrm{~cm})$ were placed on stubs using carbon tapes. Further, these samples were sputter coated with gold and observed under SEM at $200 \mathrm{kV}$. The nanofibers were characterized using Fourier transform infrared spectroscopy (FTIR, 400-4000 cm-1 range, IR affinity 1S series, Shimadzu, Japan), X-ray diffraction (XRD) using Empyrean Malvern Panalytical diffractometer $(\mathrm{Cu}$ Ka radiation, 1.54 Å), and Raman spectroscopy (532 nm laser, WITec Alpha300RA, Germany).

Crosslinking of prepared F-CNF in the polymeric nanocomposite samples was analyzed using FTIR. The thicknesses of nanocomposite films were measured using digital micrometre (Mitutoyo, Japan). The nanocomposite films were subjected to electrical resistance measurement using a computer aided multimeter (GW Instek GDM8246, Goodwill Inc., Taiwan), impedance analyser (E4990A, Keysight Technologies, USA). The impedance of the nanocomposite films was tested in parallel plate method equipped with a dielectric test fixture (16451B, $45 \mathrm{~mm}$ diameter). The instrument was calibrated before testing and the samples were placed in between the probe in parallel setup. The impedance of the samples was measured in the frequency range of $20 \mathrm{~Hz}-20 \mathrm{MHz}$ and the absolute values were plotted against frequency. The mechanical property of developed samples (cut into $1 \times 5 \mathrm{~cm}$ ) was studied by analyzing Tensile strength of the samples.

\section{Results And Discussion}

- $\quad$ Scanning Electron Microscopy (SEM)

SEM was carried out for functionalized carbon nanofibers. The diameter of CNF is in the range of $100 \mathrm{~nm}$ and its length is $20-100 \mathrm{~mm}$. The increase in acid functionalized CNF diameters indicates that the CNF is preferentially oriented towards the length of the nanofibre. 


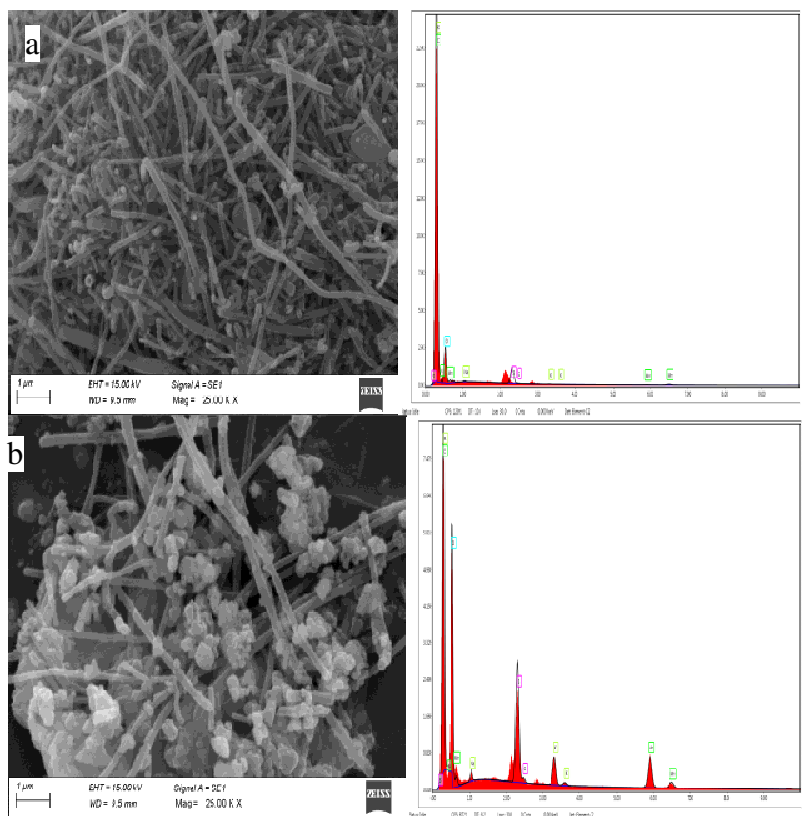

Fig. 2. SEM images of (a) P-CNF and (b) F-CNF.

SEM was carried out for pristine carbon nanofiber and functionalized carbon nanofibers under optimized condition. The CNFs have a range of up to several micrometres, according to SEM observations. Some impurities can be seen on the surface of pristine CNF, which may be caused by residual metallic catalysts during production process. Intercalated and exfoliated graphites with a higher number of oxidation sites on carbon atoms can be produced by treating CNFs with a concentrated acidic solution. On the side wall and at the end of the tube, oxidised sites may form, and defects in the hexagonal crystalline structure may allow strong acid mixtures to attack and form oxygen-containing functional groups. The EDX results of P-CNF showed approximately $73.88 \mathrm{wt}$. \% carbon, $5.85 \mathrm{wt}$. \% nitrogen, and

$17.09 \mathrm{wt} \%$ oxygen, corresponding to $79.52,5.4$, and 13.81 at.\% respectively. The EDX results of CNF showed approximately $42.36 \mathrm{wt}$. \% carbon, $3.34 \mathrm{wt} . \%$ nitrogen,

$30.12 \mathrm{wt} \%$ oxygen, $0.59 \mathrm{wt} \%$ sodium, $7.91 \mathrm{wt} \%$ sulfur, $3.1 \mathrm{wt} \%$ potassium and 12.58 $\mathrm{wt} \%$ manganese corresponding to $56.63,3.82,30.22,0.41,3.96,1.27$ and 3.68 at. $\%$ respectively.

- $\quad X-R A Y$ Diffraction (XRD) Analysis

XRD used to analyze the crystallites form in CNF and functionalized CNF. XRD peak presents order on the extended range and crystal structure arrangement. According Tang et al. $2012,26.5^{\circ}$ peak corresponds to the $\left(\begin{array}{lll}0 & 0 & 2\end{array}\right)$ peak of carbon nanofibers.

\section{Raman Spectroscopy}




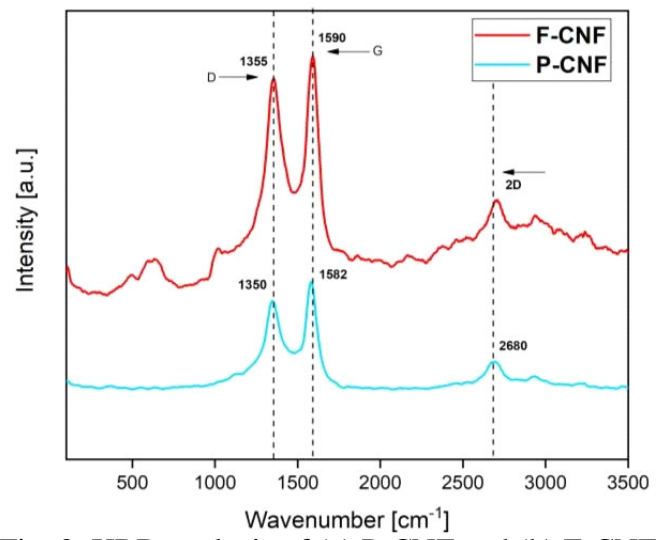

Fig. 3. XRD analysis of (a) P-CNF and (b) F-CNF.

The presence of peaks at $2 \theta=35.5^{\circ}, 44^{\circ}$ and $62.7^{\circ}$ corresponding to (110), (101) and (103) diffraction planes confirmed the acid functionalization of CNFs. After functionalization, similar crystalline structures were obtained, indicating that the introduction of oxygen surface

Fig. 5. Raman spectra showing the positions of G-, D- and 2D-bands in P- CNF and FCNF.

Figure 4 shows the Raman spectra of CNF and F-CNF. G-band peak (1580-1600 cm-1) appeared due to in-plane bond stretching of carbon atom $\mathrm{sp}^{2}$ hybridization. The presence of a broad $\mathrm{G}$ band at $1582 \mathrm{~cm}-1$ and a D band at groups on the surface does not modify structure of the bulk CNFs.

- Fourier-transform infrared spectroscopy

The crystalline $1350 \mathrm{~cm}-1$ was observed. It is noteworthy that the intensity of the D band is comparable to that of the $\mathrm{G}$ band suggesting the presence of defects in the specimen. Upon acid functionalization, the $\mathrm{G}$ band of graphene upshifted from 1582 to $1590 \mathrm{~cm}-1$, signifying the occurrence of electron transfer (S. Wang et al. 2011). The three separate bands of CNF at $1335 \mathrm{~cm}-1,1570 \mathrm{~cm}-1$ and $2675 \mathrm{~cm}-1$ were attributed to the D, G and 2D bands, respectively (Cho et al. 2015).

- Impedance analysis of CNF/Gelatin

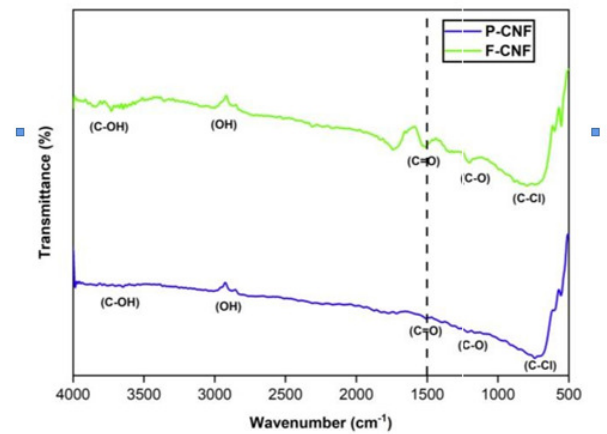

Fig. 4. Spectrum analysis of CNF. 
Figure 4 shows the typical FTIR spectrum obtained for P- CNF and F-CNF. Both samples show a strong and broad peak from $2890-3000 \mathrm{~cm}^{-1}$, which corresponds to the stretching mode of the O-H group (Vinayan et al. 2011). In functionalized CNF, the peak at $3650 \mathrm{~cm}^{-1}$ is due to $\mathrm{C}-\mathrm{OH}$ stretching vibrations and the peak at $1243 \mathrm{~cm}^{-1}$ is due to $\mathrm{C}-\mathrm{O}$ stretching vibrations (Eswaraiah et al. 2011, Kunping et al. 2010). The band at $1500 \mathrm{~cm}^{-1}$ is due to $\mathrm{C}=\mathrm{O}$ stretching and the band at $680 \mathrm{~cm}^{-1}$ is due to $\mathrm{C}-\mathrm{Cl}$ stretching vibrations ( $\mathrm{Li}$ et al. 2011, Kunping et al. 2010).

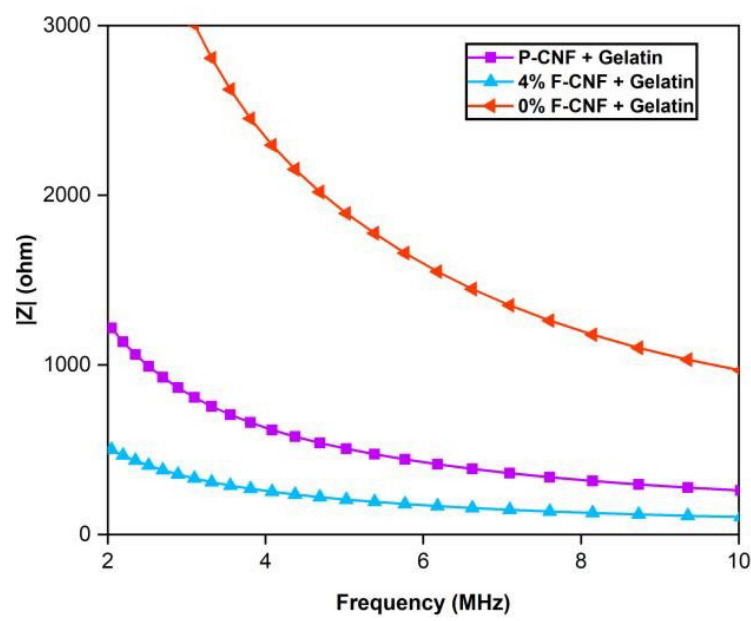

Fig. 6. Impedance analysis of CNF/gelatin nanocomposite films

The impedance of three nanocomposite films measured in frequency, ranging from $20 \mathrm{~Hz}$ - 20 MHz. MHz. In Figure 6, among the CNF based nanocomposite films, 4\% F-CNF showed better linear impedance or frequency-independent electrical conductivity over the frequency range, which network on the polymer nanocomposites.

- Tensile Strength of CNF/Gelatin

Tensile strength was carried out on strip shaped $(1 * 50 \mathrm{~mm}$, thickness determined by digital micrometer). The test was performed both in dry and wet (immersion in DI water) conditions.

- Dry sample

Samples (0\% F-CNF, 4\% F-CNF and P-CNF) were used. The elasticity of $4 \%$ F-CNF, $0 \% \mathrm{~F}-\mathrm{CNF}$ and P- CNF/Gelatin films is around $36 \mathrm{~N}, 29 \mathrm{~N}$ and $20 \mathrm{~N}$, respectively with extension from 0 to $0.8 \mathrm{~mm}$. In this study, an increase of $7 \mathrm{~N}$ and $16 \mathrm{~N}$ were observed with respect to $4 \% \mathrm{~F}-\mathrm{CNF} / \mathrm{Gelatin}$ film when compared to $0 \% \mathrm{~F}-\mathrm{CNF}$ and P-CNF, respectively. Using the plot, Stress (MPa) and Strain (\%) were calculated, mentioned in Table II. 


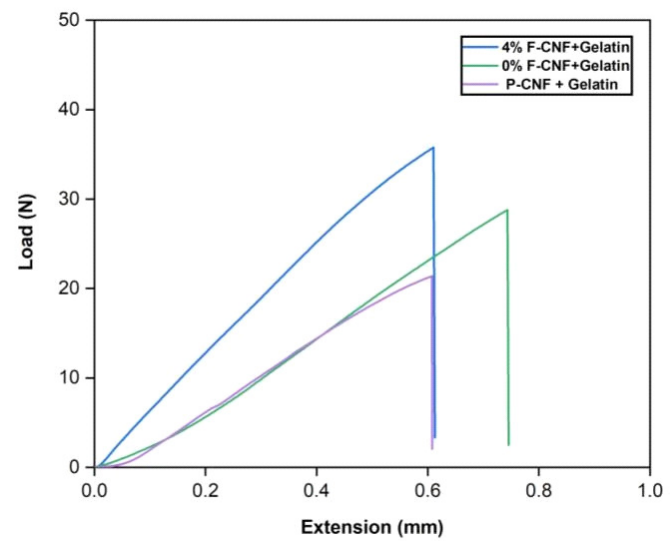

Fig. 7. Tensile strenght of CNF/Gelatin nanocomposite films (Dry state)

TABLE II. TENSILE STRENGTH OF CNF/GELATIN FILM (DRY STATE)

\begin{tabular}{|l|l|l|l|l|l|}
\hline Sample & $\begin{array}{l}\text { Load } \\
(\mathbf{N})\end{array}$ & $\begin{array}{l}\text { Thickness } \\
(\mathbf{m m})\end{array}$ & $\begin{array}{l}\text { Stress } \\
(\mathbf{M P a})\end{array}$ & $\begin{array}{l}\text { Extension } \\
(\mathbf{m m})\end{array}$ & $\begin{array}{l}\text { Strain } \\
\%\end{array}$ \\
\hline $\begin{array}{l}\text { 0\%-F- } \\
\text { CNF/Gelatin }\end{array}$ & 29 & 0.137 & 21.168 & 0.72 & 1.50 \\
\hline $\begin{array}{l}4 \%-F-C N F / \\
\text { Gelatin } \\
\text { P-CNF/ } \\
\text { Gelatin }\end{array}$ & 36 & 0.171 & 21.053 & 0.62 & 1.24 \\
\hline
\end{tabular}

- Wet sample

Samples (0\% F-CNF, 4\% F-CNF and P-CNF) were used. The elasticity of $4 \%$ F-CNF, $0 \% \mathrm{~F}-\mathrm{CNF}$ and $\mathrm{P}-\mathrm{CNF} / \mathrm{Gelatin}$ films is around $1.6 \mathrm{~N}, 0.8 \mathrm{~N}$ and $1.4 \mathrm{~N}$, respectively with extension from 0 to $20 \mathrm{~mm}$. In this study, an increase of $0.6 \mathrm{~N}$ and $0.4 \mathrm{~N}$ were observed with respect to $4 \% \mathrm{~F}-\mathrm{CNF} / \mathrm{Gelatin}$ film when compared to $0 \% \mathrm{~F}-\mathrm{CNF}$ and P-CNF, respectively. Using the plot, Stress (MPa) and Strain (\%) were calculated, mentioned in Table III. 


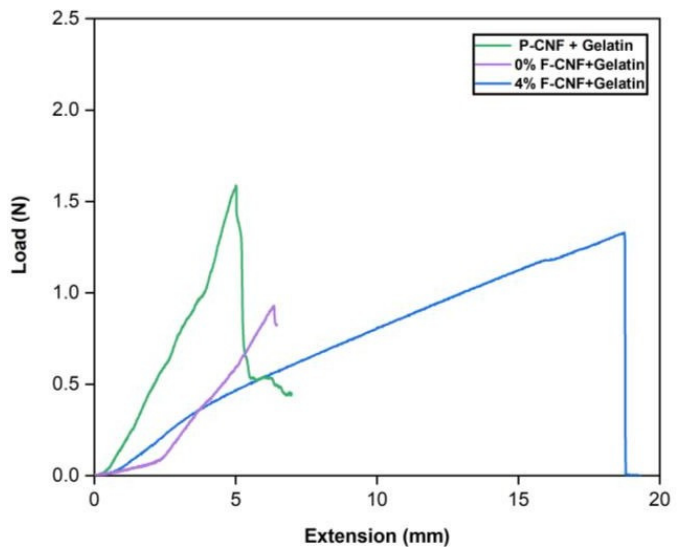

Fig. 8. Tensile strenght of CNF/Gelatin nanocomposite films (Wet state)

TABLE III. TENSILE STRENGTH OF CNF/PVA FILM (WET STATE)

\begin{tabular}{|l|l|l|l|l|l|}
\hline Sample & $\begin{array}{l}\text { Load } \\
(\mathbf{N})\end{array}$ & $\begin{array}{l}\text { Shickness } \\
(\mathbf{m m})\end{array}$ & $\begin{array}{l}\text { Stress } \\
(\mathbf{M P a})\end{array}$ & $\begin{array}{l}\text { Extension } \\
(\mathbf{m m})\end{array}$ & $\begin{array}{l}\text { Strain } \\
\%\end{array}$ \\
\hline $\begin{array}{l}\text { 0\% F-CNF/ } \\
\text { Gelatin }\end{array}$ & 0.8 & 0.137 & 0.5839 & 6 & 12 \\
\hline $\begin{array}{l}\text { 4\% F-CNF/ } \\
\text { Gelatin }\end{array}$ & 1.6 & 0.171 & 0.9357 & 19 & 38 \\
\hline $\begin{array}{l}\text { P-CNF/ } \\
\text { Gelatin }\end{array}$ & 1.4 & 0.127 & 1.1024 & 5 & 10 \\
\hline
\end{tabular}

- $\quad$ Impedance analysis of CNF/PVA

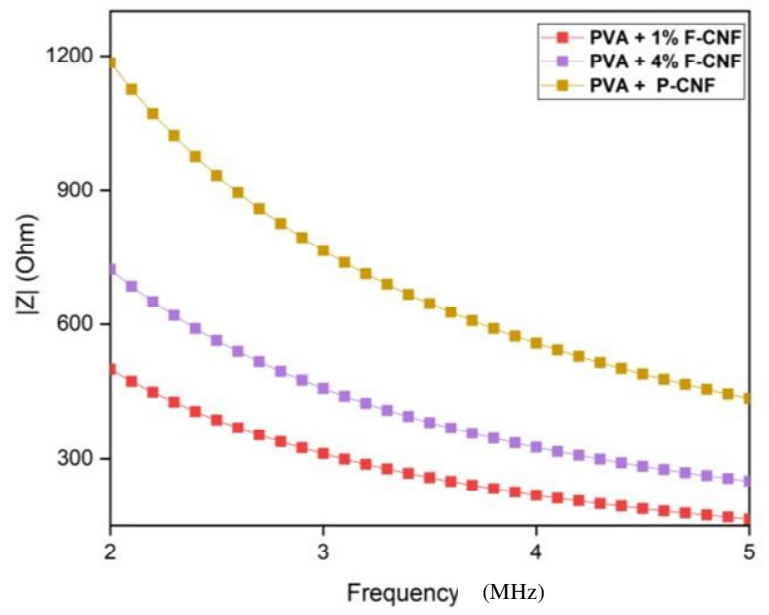

Fig. 9. Impedance analysis of CNF/PVA nanocomposite films 
The impedance of the three nanocomposite films measured in frequency, ranging from 20 $\mathrm{Hz}-20 \mathrm{MHz}$. In Figure 9, among the CNF based nanocomposite films, 4\% F- CNF showed better conductivity though it is not frequency- independent.

\section{- $\quad$ Tensile Strength of $C N F / P V A$}

Tensile strength was carried out on strip shaped $(1 * 50 \mathrm{~mm}$, thickness determined by digital micrometer). The test was conditions.

- Dry sample

Samples (0\% F-CNF, 4\% F-CNF and P-CNF) were used. The elasticity of $4 \%$ F-CNF, $0 \% \mathrm{~F}-\mathrm{CNF}$ and $\mathrm{P}-\mathrm{CNF} / \mathrm{PVA}$ films is around $24 \mathrm{~N}, 45 \mathrm{~N}$ and $35 \mathrm{~N}$, respectively with extension from 0 to $50 \mathrm{~mm}$. In this study, an increase of $5 \mathrm{~N}$ and $10 \mathrm{~N}$ were observed with respect to $4 \% \mathrm{~F}-\mathrm{CNF} / \mathrm{PVA}$ film when compared to $0 \% \mathrm{~F}-\mathrm{CNF}$ and $\mathrm{P}-\mathrm{CNF}$, respectively. Using the plot, Stress (MPa) and Strain (\%) were calculated, mentioned in Table IV.

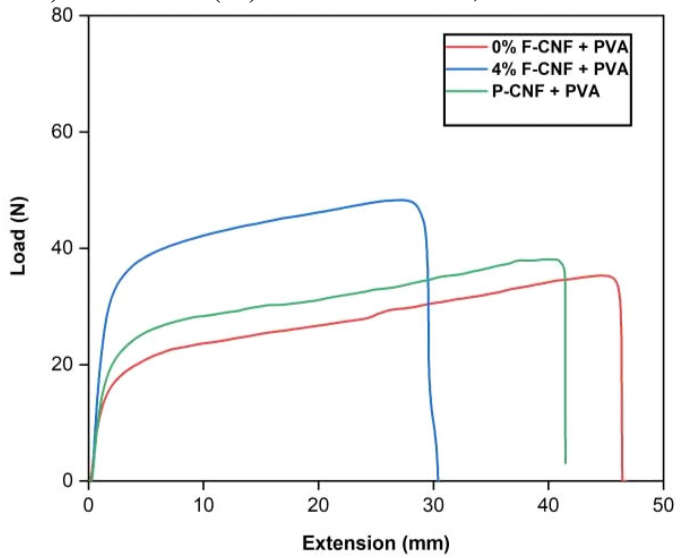

Fig. 10. Tensile strenght of CNF/PVA nanocomposite films (Dry state)

TABLE IV. TENSILE STRENGTH OF DIFFERENT COMPOSITION OF
\begin{tabular}{|l|l|l|l|l|l|}
\hline Sample & $\begin{array}{l}\text { Load } \\
\text { (N) }\end{array}$ & $\begin{array}{l}\text { Thicknes } \\
\mathbf{s}(\mathbf{m m})\end{array}$ & $\begin{array}{l}\text { Stress } \\
(\mathbf{M P a})\end{array}$ & $\begin{array}{l}\text { Extensio } \\
\mathbf{n}(\mathbf{m m})\end{array}$ & $\begin{array}{l}\text { Strain } \\
\%\end{array}$ \\
\hline $\begin{array}{l}\text { 0\%-F- } \\
\text { CNF/PVA }\end{array}$ & 38 & 0.088 & 43.182 & 46 & 92 \\
\hline $\begin{array}{l}\text { 4\%-F- } \\
\text { CNF/PVA } \\
\text { P- } \\
\text { CNF/PVA }\end{array}$ & 48 & 0.101 & 47.525 & 30.5 & 61 \\
\hline
\end{tabular}

- Wet Samples (0\% F-CNF, 4\% F-CNF and P-CNF) were used. The elasticity of $4 \%$ F$\mathrm{CNF}, 0 \% \mathrm{~F}-\mathrm{CNF}$ and P-CNF/PVA films is around $10 \mathrm{~N}, 40 \mathrm{~N}$ and 15 , respectively with extension from 0 to $0.8 \mathrm{~mm}$. In this study, an increase of $30 \mathrm{~N}$ and $25 \mathrm{~N}$ were observed with 
respect to $4 \% \mathrm{~F}-\mathrm{CNF} / \mathrm{PVA}$ film when compared to $0 \% \mathrm{~F}-\mathrm{CNF}$ and $\mathrm{P}-\mathrm{CNF}$, respectively. Using the plot, Stress (MPa) and Strain (\%) were calculated, mentioned in Table V.

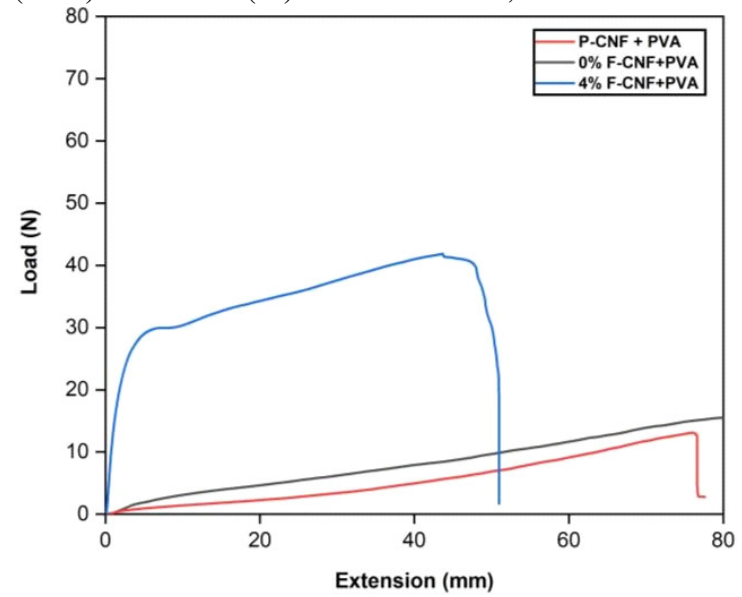

Fig. 11. Tensile strenght of CNF/PVAnanocomposite films (wet state)

TABLE V. TENSILE STRENGTH OF CNF/PVA FILM (WET STATE)

\begin{tabular}{|l|l|l|l|l|l|}
\hline Sample & $\begin{array}{l}\text { Load } \\
(\mathbf{N})\end{array}$ & $\begin{array}{l}\text { Thickness } \\
(\mathbf{m m})\end{array}$ & $\begin{array}{l}\text { Stress } \\
\text { (MPa) }\end{array}$ & $\begin{array}{l}\text { Extension } \\
(\mathbf{m m})\end{array}$ & $\begin{array}{l}\text { Strain } \\
\%\end{array}$ \\
\hline $\begin{array}{l}\text { 0\%-F- } \\
\text { CNF/PVA }\end{array}$ & 18 & 0.088 & 20.454 & 80 & 160 \\
\hline $\begin{array}{l}4 \%-F- \\
\text { CNF/PVA }\end{array}$ & 41 & 0.101 & 40.594 & 51 & 102 \\
\hline $\begin{array}{l}\text { P- } \\
\text { CNF/PVA }\end{array}$ & 16 & 0.151 & 10.596 & 79 & 158 \\
\hline
\end{tabular}

\section{Conclusion}

The main aim of this study was to analyze the effect of hydrogel formed via acid functionalized $\mathrm{CNF}$ as a crosslinker in the conducting nanocomposite. The CNF based conducting nanocomposites with gelatin and PVA, were developed in different concentrations $(0 \%, 4 \%, \mathrm{P}-\mathrm{CNF})$. The nanocomposite films showed excellent mechanical property, low swelling and solubility and good porosity.

In comparison with conventional nano-based electrodes, the current work with F-CNF based conducting nanocomposite hydrogel patch has better performance which involves usage of less harsh chemicals. It can efficiently monitor biosignals, such as in electromyography and electroencephalography. Functionality such as mechanical property and electrical property of the prepared hydrogel on ECG electrode application was analyzed. 4\% F- CNF/polymeric nanocomposite shown to be better 


\section{References}

[1] Huang, C. and Cheng, Q., 2017. Learning from nacre: Constructing polymer nanocomposites. Composites Science and Technology, 150, pp.141-166.

[2] Jung, H., Kwon, D., Lee, S., Ahn, J., Kim, A.H., Kim, Y.J. and Moon, J., 2018, August. Carbon based electrode for wearable biosignal monitoring patch. In 2018 International Flexible Electronics Technology Conference (IFETC) (pp. 1-2). IEEE.

[3] Vajtai, R. ed., 2013. Springer handbook of nanomaterials. Springer Science \& Business Media.

[4] Sonker, A.K., Roy, S., Wagner, H.D., Zak, A., Sui, X. and Bajpai, R., 2020. Synergistic effect of crosslinking and dual reinforcement on the thermal and mechanical properties of polyvinyl alcohol. Polymer Composites.

[5] A. S. Hickey, N. A. Peppas, J. Membr. Sci. 1995, 107, 229.

[6] Y.-L. Wang, H. Yang, Z.-L. Xu, J. Appl. Polym. Sci. 2007, 107, 1423.

[7] Zeng, L., Huang, X., Li, X., Li, R., Li, Y. and Xiong, Y., 2020. A gelatin-treated carbon nanofiber/epoxy nanocomposite with significantly improved multifunctional properties. Materials Today Communications, 24, p.101006.

[8] Mehrabi, A., Baheiraei, N., Adabi, M. and Amirkhani, Z., 2020. Development of a novel electroactive cardiac patch based on carbon nanofibers and gelatin encouraging vascularization. Applied biochemistry and biotechnology, 190(3), pp.931-948.

[9] Gao, W., Guo, J., Xiong, J., Smith, A.T. and Sun, L., 2018. Improving thermal, electrical and mechanical properties of fluoroelastomer/amino-functionalized multi-walled carbon nanotube composites by constructing dual crosslinking networks. Composites Science and Technology, 162, pp.49-57.

[10] Hummers Jr. W. S., Offeman R. E.: Preparation of graphitic oxide. Journal of the American Chemical Society, 80, 1339 (1958). DOI: 10.1021/ja01539a017

[11] Said, Z., Allagui, A., Abdelkareem, M.A., Alawadhi, H. and Elsaid, K., 2018. Acid-functionalized carbon nanofibers for high stability,

[12] thermoelectrical and electrochemical properties of nanofluids. Journal of colloid and interface science, 520 , pp.50-57.

[13] J Sebastián, D., Suelves, I., Moliner, R. and Lázaro, M.J., 2010. The effect of the functionalization of carbon nanofibers on their electronic conductivity. Carbon, 48(15), pp.4421-4431.

[14] Li, P., Zhao, T.J., Zhou, J.H., Sui, Z.J., Dai, Y.C. and Yuan, W.K., 2005. Characterization of carbon nanofiber composites synthesized by shaping process. Carbon, 43(13), pp.2701-2710.

[15] Eom, H., Joo, H.J., Kim, S.C. and Kim, S.S., 2020. Properties of carbon-based nanofiber with Pd and its application to microbial fuel cells electrode. Environmental Technology \& Innovation, 19, p. 100800 .

[16] Kara, S., Konal, M., Ertaş, M. and Uzunoğlu, C.P., 2017, October. The electrical characteristics of electroconductive gels used in biomedical applications. In 2017 Medical Technologies National Congress (TIPTEKNO) (pp. 1-4). IEEE.

[17] Salski, B., Krupka, J. and Kopyt, P., 2014. Measurement of sheet resistance of GaN films on a dielectric substrate. The European Physical Journal Plus, 129(8), pp.1-9.

[18] Dynamic Mechanical Analysis of Hydrogel

[19] Al-Saleh, M.H. and Sundararaj, U., 2011. Review of the mechanical properties of carbon nanofiber/polymer composites. Composites Part A: Applied Science and Manufacturing, 42(12), pp.2126-2142. 